\title{
Extension of the stimulus control produced by three procedures for teaching pseudowords discrimination*
}

\author{
Jonathan Melo de Oliveira ${ }^{1,2, * *}$ (1) \& Elenice Seixas Hanna ${ }^{1}$ (1) \\ ${ }^{1}$ Universidade de Brasília, Brasília, DF, Brasil \\ ${ }^{2}$ Centro Universitário de Brasília, Brasília, DF, Brasil
}

\begin{abstract}
This study investigated the effects of pseudoword discrimination training that either required or didn't require selection responses upon control by stimulus elements and recombination of elements, and upon stimulus observation. Eight undergraduate students were exposed to two conditions with discriminative training and stimulus control test. Condition SEL required selecting the $\mathrm{S}+$, and condition OBS only required observation. Test results suggest that selection responses did not affect control by the elements or the recombination of elements in the pseudowords. Four participants presented restricted stimulus control. This control was extended in the additional DOR condition, which required differential observation of the elements, and was accompanied by increases in S+ observation. Increased stimulus control, promoted by the DOR, should still be evaluated independently of previous teaching conditions.
\end{abstract}

KEYWORDS: Pseudoword discrimination, letter discrimination, teaching procedure, observing and selecting, restricted stimulus control, undergraduate students.

\section{Extensão do controle de estímulos produzida por três procedimentos de ensino de discriminações de pseudopalavra}

\begin{abstract}
RESUMO - Este estudo investigou o efeito de treino discriminativo de pseudopalavras com e sem a exigência de resposta de seleção sobre o controle por elementos e recombinações de elementos e sobre a observação dos estímulos. Oito universitários realizaram duas condições com treino discriminativo e teste de controle de estímulos. Na condição SEL, requeria-se uma resposta de seleção do $\mathrm{S}+$, e na condição OBS, apenas a observação. A resposta de seleção não foi determinante no controle pelos elementos e pela recombinação de elementos. Quatro participantes apresentaram controle restrito. Este controle foi ampliado na condição adicional DOR, que requeria a observação diferencial dos elementos, e foi acompanhado por aumento da observação do S+. A ampliação do controle de estímulos, ocasionada pelo DOR, ainda requer avaliação independente de condições de ensino anteriores.
\end{abstract}

PALAVRAS CHAVE: Discriminação de pseudopalavras, discriminação de letras, procedimento de ensino, selecionar e observar, controle de estímulos restrito, universitários.

Learning in the most diverse contexts often involves stimulus discrimination, which is established by reinforcing a behavior in the presence of a stimulus ( $\mathrm{S}^{\mathrm{D}}$ or $\mathrm{S}+$ ), but not in the presence of another stimulus ( $\mathrm{S}^{\Delta}$ or S-) (Matos, 1981). Responses in contingencies involving compound stimuli (i.e., stimuli with more than one relevant element) may be controlled by the different elements of the stimuli (e.g., Allen \& Fuqua, 1985; Reynolds, 1961).
Behavioral control by elements of a stimulus may benefit an organism depending on the context in which it occurs. Studies shedding light on situations in which this phenomenon is harmful often call it "attention problems" (e.g., Kooistra et al., 1996; Zentall \& Kruczek, 1988). These "problems" have been interpreted, from a behavioral-analytic standpoint, as failures to establish control by the relevant elements of a stimulus in new

\footnotetext{
* This work is part of the master's thesis of the first author, which was supported by CAPES.

**E-mail: jonmelo@gmail.com

- Submetido: 25/07/2017; Revisado: 10/09/2018; Aceito: 19/04/2019.
} 
contexts (e.g., Lovaas et al., 1971). This phenomenon has been named overselectivity by some authors (e.g., Bailey, 1981; Lovaas et al., 1979; Reed \& Gibson, 2005), while others prefer the term restricted stimulus control (e.g., Dube \& McIlvane, 1999; Walpole et al., 2007).

The overselectivity phenomenon was first described by Lovaas et al. (1966) for children identified within the Autism Spectrum Disorder. Since then, this population, along with other atypically developing populations, whether children or adults, has been associated with overselectivity (e. g., Anderson \& Rincover, 1982; Domeniconi et al., 2009; Dube, \& Mcllvane, 1997, 1999; Lovaas, \& Schreibman, 1971; Lovaas et al., 1971; Maguire et al., 1994; Pérez-González et al., 2014; Reed, 2017). The methodological procedures used with these populations commonly involve matchingto-sample tasks, which enables new relationships between stimuli to emerge (e. g., Dickson et al., 2006; Reed, 2012; Whiteley et al., 1987). According to Dube et al. (2016), the matching-to-sample task consists on presenting a multipleelement sample stimulus and then removing the sample before presenting a set of comparison stimuli.

Even though this field of study has been developed for specific populations and procedures, the occurrence of control by only part of the stimulus elements has also been documented in research with typically developed adults (e. g., Broomfield et al., 2010; Perez et al., 2015; Reed \& Gibson, 2005). As stated by Broofield et al. (2008), investigating this phenomenon in non-clinical populations is easier and allows us to analyze and develop different procedures to solve this issue before applying them on a population with atypical development.

Simple discrimination procedures with compound stimuli may also help clarify the different perspectives on the overselectivity phenomenon. McHugh and Reed (2007), for instance, conducted research to identify whether there was a relationship between participants' ages and the occurrence of overselectivity. Experiment 1 consisted of a simple discrimination task with two compound stimuli, an S + and an S-. Two S+ and two Swere used, and an $\mathrm{S}+$ was always paired with an S-. The elements consisted of meaningless symbols. In addition to the stimuli, a distraction task was included, which involved memorizing a $4 \times 4$ stimuli matrix with geometric shapes. Half of the participants from the three different age groups performed this distracting task. Ages ranged from 18 to 22,47 to 55 , or 70 to 80 years old. Restricted control was conveyed by participants from all three groups, with a positive and statistically significant correlation between overselectivity and age groups. In addition, the distraction task also correlated positively with the degree of overselectivity.
In Experiment 2, McHugh and Reed (2007) sought to increase control through the elements that did not acquire the S+ function. In this experiment, training consisted of presenting the element that was most selected by each participant in Experiment 1, as well as a new element, in separate cards. Choosing the least selected $\mathrm{S}+$ element was reinforced and choosing the most selected S- was punished. During testing, control by the elements was reversed for participants in the two younger groups, but not for those in the older group. This result demonstrates that overselectivity can occur in matching-to-sample tasks, as widely investigated in the literature (e.g., Domeniconi et al., 2009; Dube \& Mcllvane, 1997, 1999; Reed, 2006), but also in simple discrimination tasks. Moreover, it allows the identification of possible relationships with individual characteristics other than development impairments, such as age.

Learning about the environmental conditions favoring restricted control is important for developing procedures to correct partial control from the rearrangement of teaching conditions. Antecedent stimulus control of behavior may be influenced by some characteristics of discriminative training, such as frequency of reinforcement (e.g., Dube \& McIlvane, 1997), length of the retention interval in a delayed matching-to-sample task (e.g., Reed, 2006), physical similarities between stimuli (e.g., Allen \& Fuqua, 1985), existence of concurrent tasks (e.g., Reed \& Gibson, 2005), and the requirement of differential observation responses (e.g., Broomfield et al., 2008; Dube \& McIlvane, 1999; Walpole et al., 2007).

In addition to the previously mentioned characteristics, aspects of the response required to teach discrimination have been investigated. Verneque (2006) and Diniz (2009) investigated the effect of the type of response - only observing or observing and clicking on stimuli-on control by the different elements of the trained stimuli in a simple discrimination. Both studies programmed a Selection and an Observation condition, each performed by a different group of typically developed children. In the Selection condition, the participants observed and pointed at the correct stimulus out of four options shown on a computer screen. In Observation, the children observed the $\mathrm{S}+$ and S- stimuli, presented simultaneously, and then the correct stimulus $(\mathrm{S}+)$ presented individually in the same position. The stimuli differed in shape, fill pattern and background color. After discriminative training, they performed tests under each condition to analyze control by the original and recombined compound stimuli and by their elements. The study conducted by Diniz differed from Verneque by adding a response screen after the stimulus presentation screen. In the Verneque study, the children responded by pointing at the stimulus, while in Diniz the children 
pointed at the white window on the response screen, which was in the same position as the stimulus presented in the previous screen. This change enabled controlling the time of exposure to the stimuli, which no longer depended on response latency under both conditions. Both experiments showed that: (1) there was no systematic difference in results between conditions with or without the selection response; and (2) control was restricted to some of the $\mathrm{S}+$ elements in the test for some participants. In Diniz's study (2009), these participants were exposed to additional training that alternated trials with compound stimuli and trials with their elements, adapted from the Differential Observing Response (DOR) training (Dube \& McIlvane, 1999). The results demonstrated that DOR extended behavioral control for all elements of the original $\mathrm{S}+$ compound.

Analyzing the occurrence of overselectivity through different methodologies, and involving different contingencies, is important to improve our understanding of restricted control and its relation to response requirements. In addition, investigating which aspects modulate the recombination of elements may also assist in the development of teaching procedures for applied issues such as the development of recombinative reading skills (i.e., combining and recombining symbols) (Hanna et al., 2010). Recombinative generalization refers precisely to this process of recombining previously learned linguistic units, in which the control of behavior by the elements remains precise and adequate (Hanna et al., 2010; Goldstein, 1983, 1993; Wetherby \& Striefel, 1978). Investigating the procedures employed in conditions that use words formed by symbols brings the experimental conditions closer to real classroom teaching conditions. This may lead to applied benefits in teaching different populations, whether they are typically or atypically developed adults or children.

This study analyzed the effect of the selection response requirement during discriminative training on the extent of behavioral control established by the elements and their recombination of taught stimuli. We conducted a systematic replication of Diniz (2009), which compared the effects of two procedures to teach discrimination between figures, with and without selection response requirements. Diniz analyzed the behavior of children and used figures composed by shape, fill pattern, and background color. In the present study, we verified the generality of Diniz's results for college students and for pseudowords composed of three letters. In both studies, the extent of stimulus control was assessed in tests showing the elements and recombination of the stimulus elements. In the present study we also monitored stimulus observation by recording eye fixation coordinates. This additional behavioral measure allowed us to compare the conditions with and without selection responses. Diniz had to conduct tests in both conditions with the selection response to enable comparisons. In this study, recording the selection and observation responses made it possible to maintain the same procedures (with and without selection) during training and testing, and to verify whether, under selection conditions, changes in the observation of the S+ and S- stimuli would follow increases in discrimination accuracy.

This study assessed whether college students would show, as the children in Diniz (2009), restricted control to some elements of the original $\mathrm{S}+$, in both experimental conditions. Because in the present study some participants' behavior was under control of part of the stimulus elements, we replicated the DOR training condition to observe a possible reduction in restricted control.

Due to the choice of adult participants, two procedural changes were made in the present study, as compared to the procedure employed by Diniz (2009), in order to avoid a ceiling effect and to make the task more entertaining. First, we reduced the time of exposure to stimuli from $3 \mathrm{~s}$ to $1.5 \mathrm{~s}$; second, we used stimuli that resembled pseudowords instead of filled shapes on a colored background.

\section{METHOD}

\section{Participants}

Four women and four men, aged 18 and 24 years old $(\mathrm{M}=20.25$ years $)$ were invited to participate in the experiment. They were recruited from introductory Psychology courses at the University of Brasilia. Three participants had some level of visual impairment. They were asked to wear contact lenses during the experiment to maintain similar visual acuity for all participants. Participants signed the Informed Consent Form prior to the beginning of the study. The research was approved by the Research Ethics Committee of the Institute of Human Sciences (Comitê de Ética em Pesquisa do Instituto de Ciências Humanas - CEP/IH) of the University of Brasilia (Certificate of Presentation for Ethical Appraisal No. 18644913.1.0000.5540). 


\section{Location, Materials and Equipment}

Data collection took place in a room $(5 \mathrm{~m} \mathrm{x} 3 \mathrm{~m})$ of the Annex of the Human Learning Laboratory at the University of Brasilia, with two tables set in an L-shape and two chairs. The participant sat at one end of the " $L$ " while the experimenter positioned himself at the other end. In front of the participant, on the table, was a chin rest, the eye-tracking camera (Tabletop Eye Imager), and a computer. The chin rest was adjusted to a comfortable height for the participant. The camera lens and the chin rest were $44 \mathrm{~cm}$ apart, and the chin rest and the 17 -inch monitor were $74 \mathrm{~cm}$ apart. The monitor was $5 \mathrm{~cm}$ above table level, so that the camera, which was placed between the screen and the individual, did not jeopardize stimulus visualization.

To program the reinforcement contingencies, a computer with a Pentium 4 processor, $2.4 \mathrm{GHz}, 512 \mathrm{Mb}$ RAM, 80 GB hard drive and Windows XP 32-bit operating system with an attached optical mouse was used. The Contingência Programada (Programmed Contingency, in English) software (Hanna et al., 2014) presented stimuli and recorded responses. Eye movements were recorded by a system consisting of a computer with an Intel Core 2 Duo processor, $2.4 \mathrm{GHz}, 2$ GB RAM, $500 \mathrm{~GB}$ HD, a Windows 7 32-bit operating system and an ISCAN ETL-300 Eye Tracking Laboratory, which contained an RK-826PCI eye tracker and an RK-630PCI calibration subsystem, connected to the Tabletop Eye Imager.

A DQW Raw Data Acquisition and Analysis software (ISCAN Inc., Woburn, MA) recorded the fixation point coordinates. This program allowed the experimenter to adjust parameters for eye movement capture, to observe the participant's eye in real time, and to view a video of the participant's computer screen which presented a cursor indicating the participant's eye fixation location. The AutoScreenRecorder software by Wisdom Software Inc. captured the tracking data from the computer screen.

\section{Stimuli}

The stimulus elements were 23 letters in Alien Gantz font (Figure 1), downloaded from http://www.dafont.com/ alien-gantz.font (Figure 1). An additional letter was created to complete the required number of elements (third $\mathrm{S}+$ element of Set 2, in Figure 1). Minor changes were made to the original letters so that they had more uniform dimensions. Each letter was about $1.5 \mathrm{~cm}$ wide by $1.5 \mathrm{~cm}$ high. In the different stages of the study, the stimuli were composed of individual letters or by two or three letters, placed side by side, $1.2 \mathrm{~cm}$ apart. The stimuli were shown inside $7 \mathrm{~cm} \mathrm{x} 4$ $\mathrm{cm}$ rectangular white windows.

\section{Procedure}

Before each session, the eye tracking equipment was calibrated for the participant. The adjustment and calibration process lasted approximately 5 to $10 \mathrm{~min}$. This process was repeated during the session if necessary.

All participants were exposed to two experimental conditions, Selection (SEL) and Observation (OBS). Participants SAF, RSS, MSC, and PAL were exposed to the SEL-OBS order, and the other four (ADS, LBM, PPG, and KCS) were exposed to the reverse order. Stimulus Set 1 (Figure 1) was used in the SEL condition, while Stimulus Set 2 was used in the OBS condition. In the SEL condition, one of the four stimuli presented on the computer screen had to be selected (mouse click). In the OBS condition, the stimuli were presented, but no response was required; the participant had only to observe them. Each condition consisted of two sessions of Discriminative Training (DT) and a Stimulus Control Test (SCT). The test presented stimuli with one, two, or three of the letters used in training. This enabled us to evaluate the control exerted by the individual letters and by the pseudowords comprising different combinations of the letters. Participants showing restricted control performance in the second experimental condition (scores below $80 \%$ in the SCT) were exposed to the DOR training condition, with two training sessions using the same set of stimuli from the second condition, and the SCT.

\begin{tabular}{|c|c|c|c|c|}
\hline \multirow{2}{*}{ Set } & \multirow{2}{*}{ Compound } & \multicolumn{2}{|r|}{ Elements } & \multirow{2}{*}{ Function } \\
\hline & & First & Second Third & \\
\hline 1 & 1 & & & $\mathrm{~S}+$ \\
\hline & 2 & & & S- \\
\hline & 3 & & & S- \\
\hline & 4 & & & S- \\
\hline 2 & 1 & & & S+ \\
\hline & 2 & & & S- \\
\hline & 3 & & & S- \\
\hline & 4 & & & S- \\
\hline
\end{tabular}

Figure 1. Each stimulus set with their corresponding compounds containing three elements, and their respective functions. 
In the first session, all participants underwent pretraining to become familiar with the training that would be used under the SEL condition, as described below. Pretraining consisted of 12 trials and, instead of pseudowords, simple stimuli of geometric shapes (circle, triangle, square and diamond) were used.

Table 1 presents the stimuli used in the training and testing of each experimental condition in code form. Letters $\mathrm{F}, \mathrm{S}$, and $\mathrm{T}$ refer to the order of the element (first, second, and third) and the exemplar number is indicated by numerals 1 through 4 .

\section{Discriminative Training (DT)}

In the SEL condition, the session began with the following instructions (original instructions were in Portuguese):
Look at all windows on the next screen and search for the correct alternative. Right after that, the windows will turn white. Click on the window where the correct image was. If you get it right, the correct image will appear along with a sound. In case of an error, only the correct image will remain on the screen. When you are ready, click with your mouse to get started.

The first trial was programmed with the S+ appearing for $1.5 \mathrm{~s}$, followed by the screen with a white window, now operative, at the same position as the $\mathrm{S}+$ (forced choice). Clicking on the white window made the $\mathrm{S}+$ reappear in the same position, followed by a sound representing a correct response. The remaining trials showed four pseudowords (one S+ and three S-) on each corner of the screen (Table 1). Mouse clicks while stimuli were presented had no programmed consequences. After $1.5 \mathrm{~s}$

Table 1

Number of trials, correct stimulus (S+) and incorrect stimuli (S-) presented in each step of the discriminative training and stimulus control test of the experimental conditions

\begin{tabular}{|c|c|c|c|c|c|c|}
\hline Procedure & No. Trials & Stage & S+ & S-1 & $\mathrm{S}^{-2}$ & S- ${ }^{3}$ \\
\hline OBS and SEL training & 18 & 1 & F1S1T1 & $\mathrm{F} 2 \mathrm{~S} 2 \mathrm{~T} 2$ & F3S3T3 & F4S4T4 \\
\hline \multirow{6}{*}{$\begin{array}{l}\text { Differential Observing } \\
\text { Response (DOR) }\end{array}$} & \multirow[t]{2}{*}{6} & 1 & F1S1T1 & F2S1T1 & F3S1T1 & F4S1T1 \\
\hline & & 2 & F1 & $\mathrm{F} 2$ & F3 & $\mathrm{F} 4$ \\
\hline & \multirow[t]{2}{*}{6} & 1 & F1S1T1 & F1S2T1 & F1S3T1 & F1S4T1 \\
\hline & & 2 & S1 & $\mathrm{S} 2$ & $\mathrm{~S} 3$ & S4 \\
\hline & \multirow[t]{2}{*}{6} & 1 & F1S1T1 & F1S1T2 & F1S1T3 & F1S1T4 \\
\hline & & 2 & $\mathrm{~T} 1$ & $\mathrm{~T} 2$ & $\mathrm{~T} 3$ & $\mathrm{~T} 4$ \\
\hline \multirow{16}{*}{ Stimulus Control Test (SCT) } & 3 & 1 & F1S1T1 & $\mathrm{F} 2 \mathrm{~S} 2 \mathrm{~T} 2$ & F3S3T3 & F4S4T4 \\
\hline & 2 & 1 & F1S1T1 & F2S1T1 & F3S1T1 & F4S1T1 \\
\hline & 2 & 1 & F1S1T1 & F1S2T1 & F1S3T1 & F1S4T1 \\
\hline & 2 & 1 & F1S1T1 & F1S1T2 & F1S1T3 & F1S1T4 \\
\hline & 2 & 1 & F1S1 & F2S2 & F3S3 & F4S4 \\
\hline & 2 & 1 & F1S1 & F2S1 & F3S1 & F4S1 \\
\hline & 2 & 1 & F1S1 & F1S2 & F1S3 & F1S4 \\
\hline & 2 & 1 & F1T1 & $\mathrm{F} 2 \mathrm{~T} 2$ & F3T3 & F4T4 \\
\hline & 2 & 1 & F1T1 & F2T1 & F3T1 & F4T1 \\
\hline & 2 & 1 & F1T1 & F1T2 & F1T3 & F1T4 \\
\hline & 2 & 1 & S1T1 & $\mathrm{S} 2 \mathrm{~T} 2$ & S3T3 & S4T4 \\
\hline & 2 & 1 & S1T1 & S2T1 & S3T1 & S4T1 \\
\hline & 2 & 1 & S1T1 & S1T2 & S1T3 & S1T4 \\
\hline & 2 & 1 & $\mathrm{~F} 1$ & F2 & F3 & F4 \\
\hline & 2 & 1 & S1 & S2 & S3 & S4 \\
\hline & 2 & 1 & $\mathrm{~T} 1$ & $\mathrm{~T} 2$ & $\mathrm{~T} 3$ & $\mathrm{~T} 4$ \\
\hline
\end{tabular}

Note. Bold indicates the only element of the compound that varied among stimuli 
of stimuli presentation, the windows became white and operative. A click on the white window where the $\mathrm{S}+$ had been displayed was followed by the $\mathrm{S}+$ reappearing in the original position for $1.5 \mathrm{~s}$, along with a specific sound. If the response occurred in a window at the same position as an $\mathrm{S}$-, the sequence of events was the same, but there was no sound. Thus, the consequence indicating correct responses was the sound whenever the $\mathrm{S}+$ reappeared alone in the chosen window.

Training in the OBS condition began with the following instructions (original instructions were in Portuguese):

Look at all the windows on the next screen and search for the correct alternative. Right after that, the windows will turn white. To find out if you got it right, compare your choice with the image that will appear along with a sound. Inform the experimenter when you are ready.

The first trial presented only the $\mathrm{S}+$ while the others showed the four pseudowords. The stimuli appeared on the screen for $1.5 \mathrm{~s}$. When stimulus presentation ended, the windows became white and inoperative for $1.5 \mathrm{~s}$. At the end of this period, the $\mathrm{S}+$ reappeared in its original position for $1.5 \mathrm{~s}$ along with the sound, regardless of where the participant had looked at during the stimulus presentation. Under this condition, the mouse was not available to the participant.

In both conditions, the $\mathrm{S}+$ and $\mathrm{S}-$ windows were placed on nine different positions ( $3 \times 3$ matrix) throughout trials, balancing the number of times each stimulus appeared in each position. A 1.5-s intertrial interval (ITI), during which the screen remained gray, separated the training trials. Training consisted of two sessions with one trial in which only the correct stimulus was presented and 18 trials with four stimuli, all of which had a blue screen background.

\section{Differential Observation Response (DOR) Training}

Only four participants, who scored less than $80 \%$ in their second condition (SEL or OBS), participated in the DOR condition. Requiring (or not) selection responses in the DOR condition corresponded to the second condition. Thus, one participant (SAF) was not required to respond in the DOR condition, and three participants (ADS, PPG, and KCS) were required to produce a selection response in this condition.
In the DOR training, trials consisted of two steps. In the first (compound) step, four stimuli were presented, for $1.5 \mathrm{~s}$, containing three elements: the stimulus defined as S+ (e.g., F1S1T1) and three S- stimuli with two elements which were the same as those in the $\mathrm{S}+$ and one element which was different (e.g. F2S1T1, F3S1T1, F4S1T1). A screen with white windows followed stimulus presentation. Participants who were exposed to the SEL condition before the DOR training had to click on the white window corresponding to the $\mathrm{S}+$. Participant SAF was shown the inoperative white windows for $1.5 \mathrm{~s}$. Then, regardless of the response and without differential consequences, the second (element) step was initiated. Four stimuli comprising only the elements that varied in the first stage (e.g., F1, F2, F3, F4) were presented in windows that differed from those used in the first step. After stimulus presentation, the screen with the white windows was shown. Finally, the sound and the $\mathrm{S}+$ compound appeared after $1.5 \mathrm{~s}$ of white windows presentation for participant SAF and, for the other participants, contingent on the selection of one of the windows. The element belonging to the S+ (e.g., F1, S1, or T1) was recorded as correct in the second step. An ITI of $1.5 \mathrm{~s}$ separated the trials.

The DOR training consisted of two sessions. Each session included six trials with stimuli containing a different first element, six with a different second element, and six with a different third element in the compound and element steps (see Table 1), totaling 18 trials. All participants went through the same mixed order of trials.

\section{Stimulus Control Test (SCT)}

This test evaluated, throughout 33 trials, the control exerted by the individual letters and by the pseudowords, after the last training session in each condition. The SCT programming was identical for the three conditions, and selection responses were required. On test trials, the screen's background color was purple and there were no differential consequences for correct and incorrect responses. A response on one of the white windows ended the trial and started the 1.5-s ITI. The SCT was composed of: (a) three trials with the compound stimuli used in training; (b) six trials with stimuli composed of three elements, with a difference in only one of the elements; (c) 18 trials with two-element stimuli; and (d) six trials with the elements presented separately (see Table 1). The order of trials varied independently of the number of elements comprising the stimuli.

\section{RESULTS}

In the discriminative training phase of the SEL condition, all participants scored at least $94.4 \%$, which corresponds to 34 correct responses in 36 trials (results not shown). Out of the eight participants, four made no errors (RSS, MSC, PAL, and PPG), two made one error (SAF and KCS) and the remaining made two errors (ADS and LBM). All errors occurred in the first training session.

Figure 2 shows an analysis of OBS and SEL test results (SCT), separated by trials that varied the first, second or third letters, per participant. The left panel shows the 
participants exposed to the SEL-OBS order, while the right panel shows those exposed to the OBS-SEL order. This analysis reveals accuracy (percent correct) in trials in which the participant had to discriminate each element of the $\mathrm{S}+$. We considered trials with stimuli composed of only one element $(n=6)$; two elements, keeping one inaltered $(\mathrm{n}=12)$; and three elements, keeping two inaltered between the alternatives $(n=6)$. Trials with stimuli differing by more than one element (three trials with three elements and six trials with two elements) were excluded because they were not informative regarding the discrimination of separate elements. Table 1 allows the identification of the trials within each type. None of these stimulus combinations had been presented during training and, at this stage, for participants to produce correct responses, control by the different elements must have been developed. A score equal to or close to $100 \%$ for any of the letters means that behavior was under the control of that letter in new and in different contexts.
Only one of the letters presented perfect control (100\% accuracy) of the participants' behavior in one or in both conditions. Exceptions were participant RSS, who scored $100 \%$ in the OBS condition for two letters, and participant KCS, who did not show perfect control under any letter in both experimental conditions. The element that presented perfect control varied among participants and conditions. There were more $100 \%$ scores for the second letter (eight) than for the first and third letters (three occurrences each). Out of the 14 cases reaching $100 \%$ accuracy, six occurred in the SEL condition, and eight in the OBS condition. Participants RSS, MSC, PAL, and LBM scored above $60 \%$ with all three letters, while the other four participants (SAF, ADS, PPG, and KCS) scored under $60 \%$ with at least one of the tested letters, in both conditions.

Figure 3 shows accuracy and the cumulative tracking of the S+ and S- in the test phase of each experimental condition for the four participants who were exposed to the DOR condition. The analyses presented in Figure 3

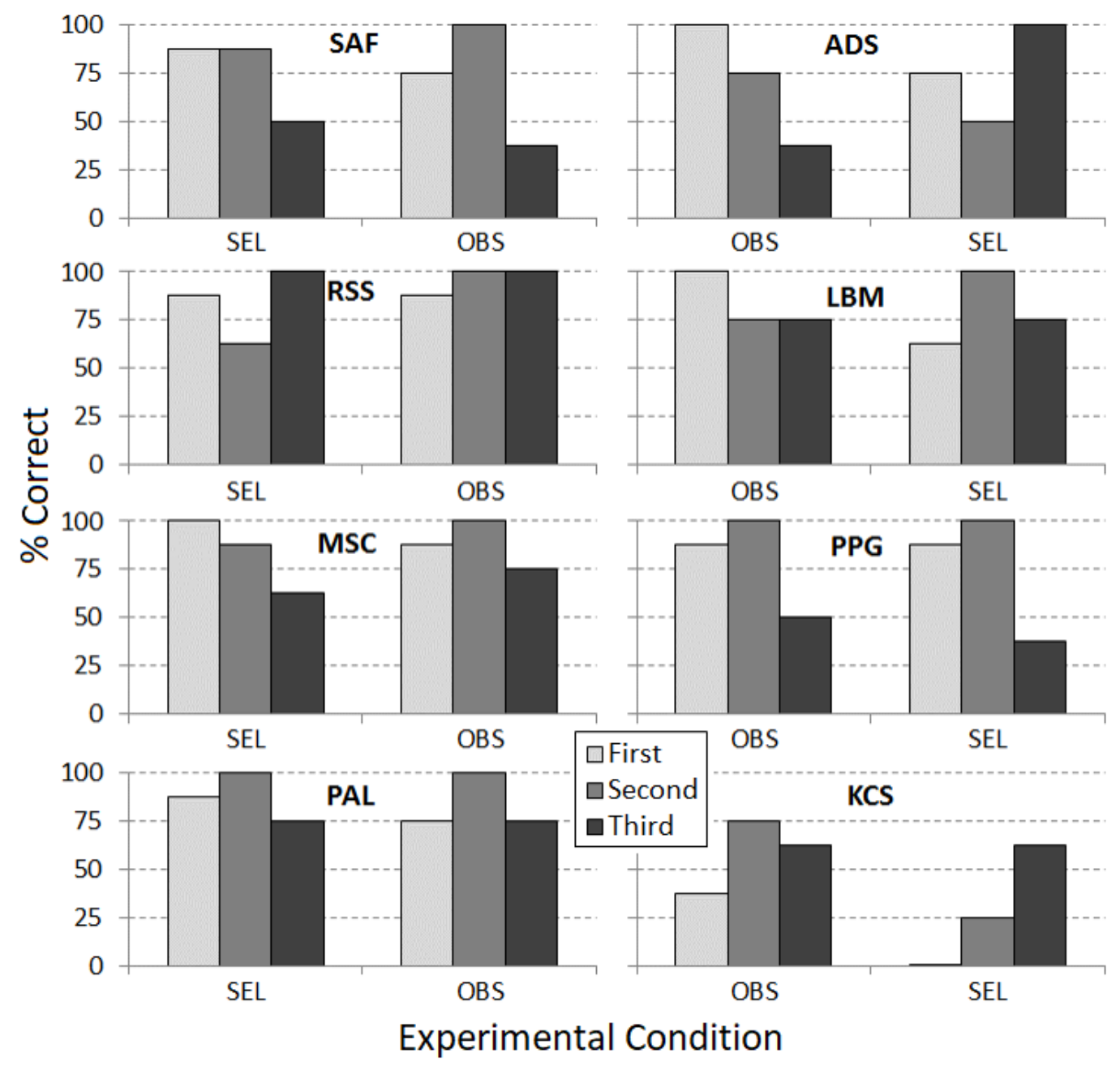

Figure 2. Accuracy of each participant in the SCT trials that varied the first, second, or third element, for each experimental condition. 


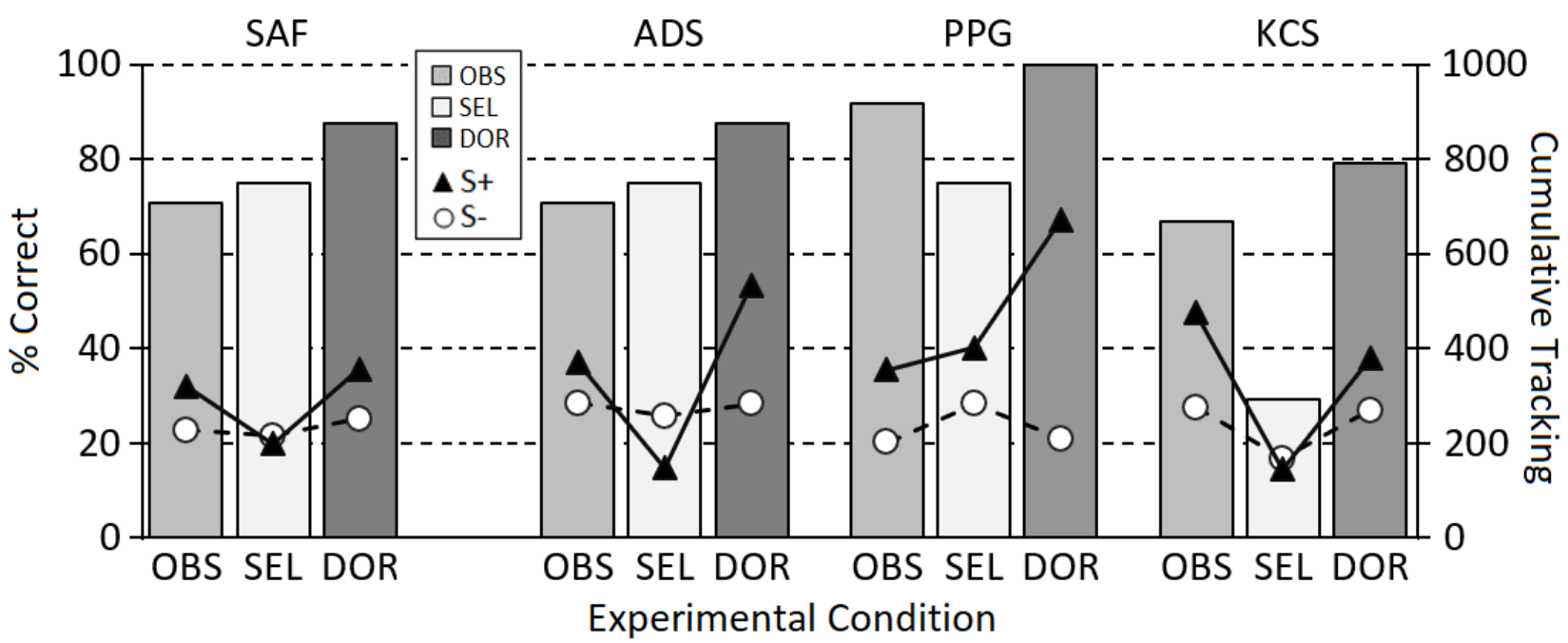

Figure 3. Accuracy and cumulative tracking of the S+ and S- in the SCT for each experimental condition and participant. Participant SAF was exposed to the SEL-OBS order, and the others were exposed to the OBS-SEL order.

comprise the same test trials from Figure 2. Participant SAF was exposed to the SEL-OBS order, and the others to the OBS-SEL order. Gray bars refer to the OBS condition, light-gray bars refer to the SEL condition, and dark-gray bars to the DOR condition. $\mathrm{S}+$ tracking is indicated by triangles and $\mathrm{S}$ - tracking is represented by circles.

Participants SAF, ADS, and KCS scored less than $80 \%$ in the SEL and OBS conditions, and participant PPG scored less than $80 \%$ only in the second condition (SEL). The differences between these conditions were not systematic: two participants had higher scores in the SEL condition when compared to the OBS condition, and two had higher scores in the OBS condition. These four participants scored highest in the DOR condition, compared to the two previous conditions. Participant KCS, despite having the lowest test performance among the four participants, showed the highest gain in the DOR condition, increasing accuracy by more than $100 \%$ in that condition as compared to the SEL one (from $29 \%$ to $79 \%$ ).

The amount of tracking in the windows containing stimuli was recorded during the test phase for all conditions and superimposed on the bars in Figure 3. Data recorded by the tracking program were 60 coordinates per second from the eye fixation point to the computer screen. The analyses considered, for each trial, records of the $1.5 \mathrm{~s}$ periods of stimulus presentation in the four windows that appeared in nine possible positions. From the window area coordinates that contained the four stimuli presented in a trial, the observations whose coordinates were contained in the area of each active window were identified and added. To compare the observation results of the three $\mathrm{S}$ - and the $\mathrm{S}+$ in a trial, the S- values of that trial were averaged. In the 33 trials of each test, up to 3036 records of eye fixation could occur. On average, $36 \%$ of the records comprised observation in the response windows (amplitude 26-44) in the test phase of OBS and SEL conditions. The four participants showed more $\mathrm{S}+$ tracking than $\mathrm{S}$ - tracking in the OBS and DOR conditions, but there were no systematic differences between $\mathrm{S}+$ and S- tracking in the SEL condition. S- observations were similar in all three conditions. Pearson's correlation between tracking and correct responses was 0.63 for the $\mathrm{S}+$, and 0.3 for the S-.

Table 2 shows the percentage of correct responses, per session, of the four participants exposed to the two steps in the DOR condition: compound and elements. Results are presented for each trained element according to its position in the compound stimulus: first (F), second (S) or third (T). For participant SAF, the DOR training did not require a selection response since their last experimental condition was OBS and, therefore, it was not possible to analyze their errors and correct responses in this task. Participants ADS and PPG produced more correct responses in the element presentation step compared to the compound step, and KCS produced similar results in both steps. All participants had higher scores in the second training session compared with the first one. For participants ADS and PPG, the element variation producing the lowest performances was the third, and for participant KCS it was the first. 
Table 2

Percentage of correct responses in DOR trials with variation of the first $(F)$, second $(S)$ and third $(T)$ elements, in steps with compound and elements

\begin{tabular}{|c|c|c|c|c|c|c|c|c|c|}
\hline \multirow{2}{*}{ Participant } & \multirow{2}{*}{ Session } & \multicolumn{4}{|c|}{ Compound } & \multicolumn{4}{|c|}{ Elements } \\
\hline & & $\mathbf{F}$ & $\mathbf{S}$ & $T$ & Average & $\mathbf{F}$ & $\mathbf{S}$ & $T$ & Average \\
\hline \multirow[t]{2}{*}{ ADS } & 1 & 83 & 83 & 58 & 75 & 75 & 92 & 92 & 86 \\
\hline & 2 & 92 & 83 & 58 & 78 & 100 & 100 & 83 & 94 \\
\hline \multirow[t]{2}{*}{ PPG } & 1 & 92 & 92 & 75 & 86 & 92 & 100 & 92 & 94 \\
\hline & 2 & 92 & 100 & 100 & 97 & 100 & 100 & 100 & 100 \\
\hline \multirow[t]{2}{*}{ KCS } & 1 & 67 & 75 & 92 & 78 & 50 & 75 & 92 & 72 \\
\hline & 2 & 67 & 83 & 92 & 81 & 58 & 75 & 100 & 78 \\
\hline \multirow[t]{2}{*}{ Average } & 1 & 81 & 83 & 75 & 80 & 72 & 89 & 92 & 84 \\
\hline & 2 & 83 & 89 & 83 & 85 & 86 & 92 & 94 & 91 \\
\hline
\end{tabular}

\section{DISCUSSION}

This study analyzed the effect of the selection response requirement during discriminative training on the extent of behavioral control established by the elements and recombination of taught stimuli, as well as on the observation of stimuli with S+ and S- functions. Half of the participants presented restricted control for one or two of the letters after pseudoword discrimination training, with and without a selection response requirement (SEL and OBS). Control by word elements increased after training that required observation of all the compound elements (DOR).

Half (four) of the participants developed control by all three elements of the pseudowords, in both the required selection (SEL) condition and the observation (OBS) condition. These results, obtained with undergraduate students using pseudowords, replicate those observed with children using stimuli composed of filled-in forms on a colored background (Diniz, 2009; Verneque, 2006). The similar effect of SEL and OBS conditions may be due to some shared aspects of these two teaching procedures. Both comprised three stages: the first presented four stimuli, the second presented the windows without the stimuli, and the third presented the correct stimulus in its original position. Additionally, observation responses occurred in both conditions. These factors may be more relevant for establishing discrimination for undergraduate students and children with some experience in discriminative learning than the selection response requirement.

The literature also reports superiority of one of these teaching procedures (with and without the selection response requirement) in stimulus equivalence tests. Clayton and Hayes (2004) and Kinloch et al. (2013), for example, reported higher test results when a selection response was required in training. On the other hand, Leader and BarnesHolmes (2001) observed higher results in the observation only condition during stimulus pairing, a respondent-type training procedure. Comparing between these studies and the present one is limited, however, by differences in training and testing procedures. While equivalence tests evaluate new relationships between trained stimuli (i.e., formation of equivalence classes), in our study the tests evaluated control by elements and the recombination of these elements. Studies on conditional discrimination teach stimuli relations, while this study taught discriminative control by one of the four presented stimuli. Additionally, in the present study, we introduced some experimental precautions, such as the control of the exposure time to stimuli, the number of training trials, and $\mathrm{S}+$ and $\mathrm{S}$ - presentations in both training conditions, while in the mentioned studies, these factors varied.

Our results suggest that the selection response does not determine control by the elements and by the stimuli composed of recombinations of these elements. These findings are relevant to improve our understanding of recombinative generalization (Goldstein, 1983, 1993; Wetherby \& Striefel, 1978) by showing control by graphic units in new configurations, based on contingencies with and without selection response requirements.

In this study, conducted with undergraduates and using a pseudoword choice task, four participants produced several errors in the test, which can be interpreted as an example of restricted control by one or two elements of a compound stimulus. Thus, the phenomenon of restricted stimulus control observed in children in previous studies (e.g. Diniz, 2009; Dube \& McIlvane, 1999; Lovaas et al., 1979) was replicated with four college students. In our study, the S+ presented in the training trials was composed of elements that differed from those of the S-. This contingency enabled correct responding in all trials based on control by any of the aspects or elements of the $\mathrm{S}+$ compound. Previous studies (Allen \& Fuqua, 1985; Birnie-Selwyn \& Guerin, 1997) have 
demonstrated that manipulating stimuli with one or more differences between them influences performance in the training and evaluating stages of control by elements. One way to reduce restricted control is to teach using stimuli with minimal differences. In the present study, restricted control decreased when four students were exposed to the DOR training, which presented stimuli with minor differences (in the compound and element steps), thus, confirming previous studies.

The ways in which stimuli are manipulated in a teaching contingency may influence observation of stimuli and their elements. Dube and collaborators (Dube et al., 2010; Dube \& McIlvane, 1999; Walpole et al., 2007) have shown that restricted control can also be modified when contingencies are programmed with a focus on observational behavior, which in turn requires stimulus manipulation. In our study, the DOR training was designed with the same purpose and caused an increase in the number of controlling elements for those participants who presented restricted control, confirming Dube and collaborators' results. It is noteworthy that in this and other studies, DOR training implies teaching a greater number of discriminations, including discriminations between elements of the compound. This difference alone can explain the improved test performance.

Increased accuracy in the DOR test was followed by increased observation of the $\mathrm{S}+$ for all four participants as compared to the previous condition that used the same stimuli. The effect of the DOR training can be described, in this case, as an increased discrimination and observation of $\mathrm{S}+$ caused by additional training. This result is in line with those obtained by Schroeder (1970) and Pessôa et al. (2009) who reported increased $\mathrm{S}+$ observation as discrimination developed.

The amount of S- tracking was similar for all three experimental conditions. It is noteworthy that the tracking analyses presented here corresponded to data from similarly programmed tests in all three experimental conditions. Two characteristics of trial programming may have contributed to the absence of change in S- observations: changes in the position of the stimulus presentation windows with each trial, and the short time participants had to emit a response. This combination of factors may have favored eye-tracking blank areas of the screen due to the unpredictability of the position of the active windows and the need to search for the stimuli, thus leaving little time to respond on the windows. The time spent looking at the stimuli seems to have been distributed equally among the four windows, with a little more time spent on the $\mathrm{S}+$ when there was behavioral control by the elements.

DOR procedures have shown to broaden control by features or elements of compound stimuli. There is empirical evidence of their relevance in teaching children with severe development impairments (e.g., Dube \& McIlvane, 1999). Nevertheless, final conclusions about the increase in accuracy observed in the DOR condition require further research in which possible effects of stimulus history and learning sets are controlled (Harlow, 1949). In ours and previous studies (Diniz, 2009; Dube \& McIlvane, 1999; Dube et al., 2010), DOR was the last condition for participants who showed restricted control in the second condition and involved the same stimuli from the previous condition. This strategy may produce carry-over effects, which could be avoided by manipulating the order of conditions and using different stimuli in each condition. Because this training has been suggested to reduce restricted control, future studies should investigate its independent effect with appropriate controls.

In sum, the present study demonstrated teaching pseudowords and recombinative generalization using contingencies that require and that do not require a selection response. Half of the participants showed restricted control by only one or two elements, but this control was extended to all three elements by using a version of the $\mid$ DOR procedure for teaching simple discriminations with compound stimuli.

\section{REFERENCES}

Allen, K. D., \& Fuqua, R. W. (1985). Eliminating selective stimulus control: A comparison of two procedures for teaching mentally retarded children to respond to compound stimuli. Journal of Experimental Child Psychology, 39, 55-71. https://doi. org/10.1016/0022-0965(85)90029-3

Anderson, N. B., \& Rincover, A. (1982). The generality of overselectivity in developmentally disabled children. Journal of Experimental Child Psychology, 34(2), 217-230. https://doi. org/10.1016/0022-0965(82)90043-1

Bailey, S. L. (1981). Stimulus overselectivity in learning disabled children. Journal of Applied Behavior Analysis, 14(3), 239-248. https://doi.org/10.1901/jaba.1981.14-239

Birnie-Selwyn, B., \& Guerin, B. (1997). Teaching children to spell: Decreasing consonant cluster errors by eliminating selective stimulus control. Journal of Applied Behavior Analysis, 30(1), 69-91. https://doi.org/10.1901/jaba.1997.30-69
Broomfield, L., McHugh, L., \& Reed, P. (2008). The effect of observing response procedures on the reduction of overselectivity in a match to sample task: Immediate but not longterm benefits. Research in Developmental Disabilities, 29, 217-234. https://doi.org/10.1016/j.ridd.2007.04.001

Broomfield, L., McHugh, L., \& Reed, P. (2010). Factors impacting emergence of behavioral control by underselected stimuli in humans after reduction of control by overselected stimuli. Journal of the Experimental Analysis of Behavior, 94(2), 125133. https://doi.org/10.1901/jeab.2010.94-125

Clayton, M. C., \& Hayes, L. J. (2004). A comparison of matchto-sample and respondent-type training of equivalence classes. The Psychological Record, 54, 579-602. https://doi. org/10.1007/BF03395493

Dickson, C. A., Deutsch, C. K., Wang, S. S., \& Dube, W. V. (2006). Matching-to-sample assessment of stimulus 
overselectivity in students with intellectual disabilities. American Journal on Mental Retardation, 111, 447-453. https://doi.org/10.1352/0895-8017(2006)111[447:MAOSO I] $2.0 . \mathrm{CO} ; 2$

Diniz, J. (2009). Avaliação do tipo de resposta requerida e do procedimento de ensino no estabelecimento de controle de estímulos compostos. Dissertação de Mestrado, Instituto de Psicologia, Universidade de Brasília, Brasília, Brasil.

Domeniconi, C., Costa, A. R. A., de Rose, J. C., \& Souza, D. G. (2009). Controle restrito de estímulos em participantes com Síndrome de Down e crianças com desenvolvimento típico. Interação em Psicologia, 13(1), 91-101.

Dube, W. V., Dickson, C. A., Balsamo, L. M., O’Donnell, K. L., Tomanari, G. Y., Farren, K. M., Wheeler, E. E., \& McIvane, W. J. (2010). Observing behavior and atypically restricted stimulus control. Journal of the Experimental Analysis of Behavior, 94(3), 297-313. https://doi.org/10.1901/jeab.2010.94-297

Dube, W. V., Farber, R. S., Mueller, M. R., Grant, E., Lorin L. \& Deustch, C. K. (2016). Stimulus overselectivity in autism, down syndrome, and typical development. American Journal on Intellectual and Developmental Disabilities, 121(3), 219235. https://doi.org/10.1352/1944-7558-121.3.219

Dube, W. V., \& McIlvane, W. J. (1997). Reinforcer frequency and restricted stimulus control. Journal of the Experimental Analysis of Behavior, 68, 303-316. https://doi.org/10.1901/ jeab.1997.68-303

Dube, W. V., \& McIlvane, W. J. (1999). Reduction of stimulus overselectivity with nonverbal differential observing responses. Journal of Applied Behavior Analysis, 32, 25-33. https://doi. org/10.1901/jaba.1999.32-25

Goldstein, H. (1983). Training generative repertoires within agentaction-object miniature linguistic systems with children. Journal of Speech and Hearing Research, 26(1), 76-89. https:// doi.org/10.1044/jshr.2601.76

Goldstein, H. (1993). Structuring environmental input to facilitate generalized language learning by children with mental retardation. Em A. P. Kaiser \& D. B. Gray (Eds.), Enhancing children's communication: Research foundations for intervention (pp. 317-334). Paul H. Brookes.

Hanna, E. S., Batitucci, L. A. V., \& Batitucci, J. S. L. (2014). Software contingência programada: Utilidade e funcionalidades. Revista Brasileira de Análise do Comportamento, 10(1), 97-104. https://doi.org/10.18542/rebac.v10i1.3949

Hanna, E. S., Karino, C. A., Araújo, V. T. \& Souza, D. G. (2010). Leitura recombinativa de pseudopalavras impressas em pseudoalfabeto: Similaridade entre palavras e extensão da unidade ensinada. Psicologia, 21(2), 275-311. https://doi. org/10.1590/S0103-65642010000200005

Harlow, H. F. (1949). The formation of learning sets. Psychological Review, 56, 51-65. https://doi.org/10.1037/h0062474

Kinloch, J.M., McEwan, J.S.A., \& Foster, T.M. (2013). Matchingto-sample and stimulus-pairing-observation procedures in stimulus equivalence: The effects of number of trials and stimulus arrangement. Psychological Record, 63(1), 157-173. https://doi.org/10.11133/j.tpr.2013.63.1.012

Kooistra, L., Meere, J. V. D., Vulsma, T., \& Kalverboer, A. (1996) Sustained attention problems in children with early treated congenital hypothyroidism. Acta Paediatrica, 85, 425-429. https://doi.org/10.1111/j.1651-2227.1996.tb14054.x

Leader, G., \& Barnes-Holmes, D. (2001). Matching-to-sample and respondent-type training as methods for producing equivalence relations: Isolating the critical variable. The Psychological Record, 51, 429-444. https://doi.org/10.1007/BF03395407

Lovaas, O. I., Berberich, J. P., Perloff, B. F., \& Schaeffer, B. (1966). Acquisition of imitative speech in schizophrenic children. Science, 151, 705-707. https://doi.org/10.1126/ science.151.3711.705
Lovaas, O. I., Koegel, R. L., \& Schreibman, L. (1979). Stimulus overselectivity in autism: A review of research. Psychological Bulletin, 86, 1236-1254. https://doi.org/10.1037/00332909.86.6.1236

Lovaas, O. I., \& Schreibman, L. (1971). Stimulus overselectivity of autistic children in a two-stimulus situation. Behavior Research and Therapy, 9, 305-310. https://doi.org/10.1016/00057967(71)90042-8

Lovaas, O. I., Schreibman, L., Koegel, R. L., \& Rehm, R. (1971). Selective responding by autistic children to multiple sensory input. Journal of Abnormal Psychology, 77(3), 211-222. https:// doi.org/10.1037/h0031015

Maguire R.W., Stromer R., Mackay H. A., \& Demis C. A. (1994). Matching to complex samples and stimulus class formation in adults with autism and young children. Journal of Autism Development Disorder, 24(6), 753-772. https://doi. org/10.1007/BF02172284

Matos, M. A. (1981). O controle de estímulos sobre o comportamento. Psicologia, 7, 1-15.

McHugh, L., \& Reed, P. (2007). Age trends in stimulus overselectivity. Journal of the Experimental Analysis of Behaviour, 88(3), 369-380. https://doi.org/10.1901/ jeab.2007.88-369

Pessôa, C. V. B. B., Huziwara, E. M., Perez, W. F., Endemann, P., \& Tomanari, G. Y. (2009). Eye fixations to figures in a four-choice situation with luminance balanced areas: Evaluating practice effects. Journal of Eye Movement Research, 2(5), 1-6. https:// doi.org/10.16910/jemr.2.5.3

Perez, W. F., Endemann, P., Pessôa, C. V. B. B., \& Tomanari, G. Y. (2015). Assessing stimulus control with compound stimuli: Evaluating testing procedures and tracking eye fixations. Psychological Record, 65, 83-88. https://doi.org/10.1007/ s40732-014-0092-1

Pérez-González, L. A., \& Alonso-Álvarez, B. (2014). Teaching a simple discrimination using a blocked-trial procedure to overcome location overselectivity. European Journal of Behavior Analysis, 15(2), 137-147. https://doi.org/10.1080/1 5021149.2014.11434510

Reed, P. (2006). The effect of retention interval on stimulus overselectivity using a matching-to-sample paradigm. Journal of Autism and Developmental Disorders, 36, 1115-1121. https:// doi.org/10.1007/s10803-006-0148-4

Reed, P. (2012). Brief report: The effect of delayed matching to sample on stimulus over-selectivity. Journal of Autism and Developmental Disorders, 42, 1515-1519. https://doi. org/10.1007/s10803-011-1374-y

Reed, P. (2017). Over-selectivity is related to autism quotient and empathizing, but not to systematizing. Journal of Autism and Developmental Disorders, 47, 1030-1037. https://doi. org/10.1007/s10803-016-2990-3

Reed, P., \& Gibson, E. (2005). The effect of concurrent task load on stimulus over-selectivity. Journal of Autism and Developmental Disorders, 35(5), 601-614. https://doi.org/10.1007/s10803005-0004-y

Reynolds, G. S. (1961). Attention in the pigeon. Journal of the Experimental Analysis of Behavior, 4, 203-208. https://doi. org/10.1901/jeab.1961.4-203

Schroeder, S. R. (1970). Selective eye movements to simultaneously presented stimuli during discrimination. Perception \& Psychophysics, 7(2), 121-124. https://doi.org/10.3758/ BF03210147

Sidman, M., \& Tailby, W. (1982). Conditional discrimination vs. matching to sample: An expansion of the testing paradigm. Journal of the Experimental Analysis of Behavior, 37, 5-22. https://doi.org/10.1901/jeab.1982.37-5

Verneque, L. (2006). Superseletividade: Efeito do requisito de resposta e do tempo de exposição ao estímulo. Dissertação de 
Mestrado, Instituto de Psicologia, Universidade de Brasília Brasília, Brasil.

Walpole, C., Roscoe, E., \& Dube, W. V. (2007). Use of a differential observing response to expand restricted stimulus control. Journal of Applied Behavior Analysis, 40(4), 707-712. https:// doi.org/10.1901/jaba.2007.707-712

Wetherby, B. C., \& Striefel, S. (1978). Application of miniature linguistic system or matrix training procedures. In $\mathrm{R}$. Schiefellbusch (Ed.), Bases of language intervention (pp. 317-356). University Park Press.
Wolfe, J. M. (1994). Visual search in continuous, naturalistic stimuli. Vision Research, 34(9), 1187-1195. https://doi. org/10.1016/0042-6989(94)90300-X

Whiteley, J. H., Zaparniuk, J., \& Asmundson, G. J. G. (1987). Mentally retarded adolescents' breadth of attention and short-term memory processes during matching to sample discriminations. American Journal of Mental Deficiency, 92, 207-212.

Zentall, S. S., \& Kruczek, T. (1988). The attraction of color for active attention-problem children. Exceptional Children, 54(4), 357362. https://doi.org/10.1177/001440298805400411 